\title{
Single-Phase Open-Circuit Fault Operation of Bearingless Multi-Sector PM Machines
}

\author{
$1^{\text {st }}$ Zhuang Wen \\ Electrical and Electronic Engineering \\ The University of Nottingham \\ Nottingham, UK \\ zhuang.wen@nottingham.ac.uk
}

\author{
$4^{\text {th }}$ Luca Papini \\ Electrical and Electronic Engineering \\ The University of Nottingham \\ Nottingham, UK and Ningbo, China \\ Luca.Papini@nottingham.ac.uk
}

\author{
$2^{\text {nd }}$ Giorgio Valente \\ Electrical and Electronic Engineering \\ The University of Nottingham \\ Nottingham, UK \\ giorgio.valente1@nottingham.ac.uk \\ $5^{\text {th }}$ Pericle Zanchetta \\ Electrical and Electronic Engineering \\ The University of Nottingham \\ Nottingham, UK \\ pericle.zanchetta@nottingham.ac.uk
}

\author{
$3^{\text {rd }}$ Andrea Formentini \\ Electrical and Electronic Engineering \\ The University of Nottingham \\ Nottingham, UK \\ andrea.formentini@nottingham.ac.uk \\ $6^{\text {th }}$ Christopher Gerada \\ Electrical and Electronic Engineering \\ The University of Nottingham \\ Nottingham, UK and Ningbo, China \\ chris.gerada@nottingham.ac.uk
}

\begin{abstract}
This paper investigates the single-phase opencircuit fault of a bearingless multi-sector PM synchronous machine. The mathematical model of the suspension force and torque generation is developed for both healthy and faulty conditions. The model is written in a general form and it can be easily extended to any sectored PM synchronous machine. Then, a fault tolerant control strategy is proposed and verified by means of finite elements and numerical simulations. The system shows a good fault tolerant capabilities.
\end{abstract}

Index Terms-Bearingless machines, multiphase machines, PM synchronous machines, fault tolerant control.

\section{INTRODUCTION}

Bearingless Machines (BMs) are electromagnetic devices capable of producing suspension force and motoring torque with a single stator [1]. They have started attracting increasing attention since the early 1990s [2]-[4]. Bearingless motors operate without mechanical bearings, hence they present no wear due to friction. They have been employed in lubricant free applications such as chemical mixers and artificial hearts [5], [6] where perfect sterile environments have to be guaranteed. Furthermore, mechanical bearings are one of the main causes for failure in high speed motors. A solution to solve this problem is to employ Active Magnetic Bearings (AMB). However, the latter ones lead to a longer rotor shaft if compared with conventional motors, that would reduce the power density and decrease the motor critical speed. Hence, BMs which combine the features of AMB and conventional machines into a single device have been significantly investigated for high speed applications [7], [8]. Different winding arrangements have been employed for BMs [2], [9]-[11]. References [2], [12] investigate BMs with two independent winding sets to produce radial suspension force and motoring torque, respectively. When the two winding solution is employed the machine's power density results remarkably reduced as typically $30-40 \%$ of the slot area is filled with the suspension winding conductors although during normal operation only less then $5 \%$ is needed [1]. [10], [13], [14] describe BMs adopting a multiphase winding set. The latter has the advantage of combining the force and torque production in a single winding set. Furthermore, multiphase BMs possess better fault tolerant capabilities than standard three-phase ones. An example of multiphase fault tolerant BM can be found in [15] where a six-phase concentrated winding is adopted where each phase is supplied by an independent single-phase inverter. Thanks to inverters redundancy the six-phase BM can operate when one or two non-adjacent phases are open-circuited. Reference [16] then presents the results of successful operations under a threephase fault for a bearingless multiphase machine with a multi three-phase winding structure.

The machine considered in this paper is a 18 slots - 6 poles PM synchronous machine (PMSM) with triple threephase windings [17]. The winding structure employed is similar to the one adopted in [16], however a different force and torque control strategy is adopted. Indeed, in [16] the suspension force and torque generation relies on the $d-$ and $q-$ axis current of each machine winding, respectively. Therefore, the coupling effects of the force and torque production were neglected and an harmonic compensator was implemented to reduce the force ripple. Instead, the technique implemented in this work keeps into account the above mentioned coupling effects and exploits the pseudoinverse matrix to compute the reference current values which minimize the copper losses [17].

In this paper the Single-Phase Open-Circuit (SPOC) fault is investigated. The considered BM is at first modelled assuming healthy operating condition and then the open- 


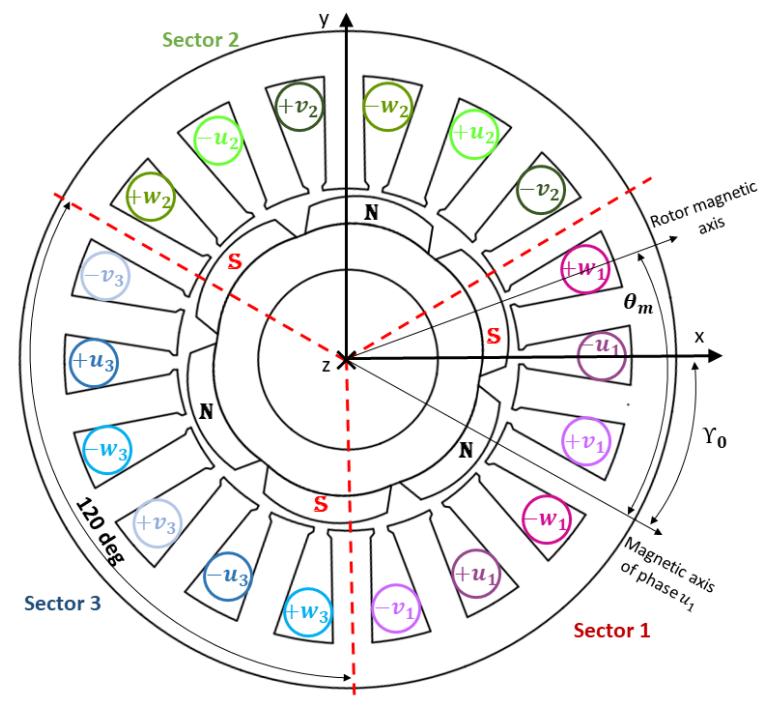

Fig. 1. Cross section of the 18 slots -6 poles PMSM with a triple independent three-phase winding.

circuit fault introduced. The healthy operating condition has been investigated and validated in [18] for the proposed BM while the three-phase open-circuit fault was presented in [19], hence the single-phase fault is the main focus of this paper. The pursued approach leads to a simple analytical formulation of the faulty machine model. Finally, FE and numerical simulation results are presented to validate the force and torque generation and the bearingless operation in case of single-phase fault in one or two machine windings.

\section{Mathematical Model of the Radial Force AND TORQUE PRODUCTION}

\section{A. The machine structure}

Figure 1 shows the cross section of the machine considered in this paper. It is a 18 slots - 6 poles surface mounted PMSM with a sectored multi three-phase winding arrangement. Each distributed three-phase winding occupies one third of the stator circumference and is fed by an independent converter. Furthermore, each of them is star connected with isolated neutral point. The machine considered in this work presents a number of sectors $n_{s}=p$, where $p$ is the pole pairs number.

The parameters of machine are shown in Table I. Furthermore, the backup mechanical bearing used in this work presents a clearance of $150 \mu \mathrm{m}$.

\section{B. Healthy condition}

The machine model is based on the assumptions of linear behaviour of the materials and magnetic decoupling of the machine sectors. The matrix expression of the radial force and torque generation can then be written in (1) as a function of the stationary reference frame current components ${ }^{s} i_{\alpha}$
TABLE I

MACHINE PARAMETERS

\begin{tabular}{l|l} 
Parameter & Value \\
\hline \hline Pole number $(2 p)$ & 6 \\
PM material & $\mathrm{NdFeB}$ \\
Power rating & $1.5[\mathrm{~kW}]$ \\
Rated Speed $\left(\omega_{\text {rated }}\right)$ & $3000[\mathrm{r} / \mathrm{min}]$ \\
Turn/coil & 22 \\
PM flux of one sector $\left({ }^{s} \Lambda_{P M}\right)$ & $0.0284[\mathrm{~Wb}]$ \\
Torque constant $\left(k_{T}\right)$ & $0.128[N \cdot m / A]$ \\
Line to line voltage constant $\left(k_{V}\right)$ & $15.5[\mathrm{~V} / \mathrm{krpm}]$ \\
Outer Stator diameter & $95[\mathrm{~mm}]$ \\
Inner Stator diameter & $49.5[\mathrm{~mm}]$ \\
Axial length & $90[\mathrm{~mm}]$ \\
Airgap length & $1[\mathrm{~mm}]$ \\
Magnets thickness & $4[\mathrm{~mm}]$
\end{tabular}

and ${ }^{s} i_{\beta}$ of each sector $s$, and rotor radial displacement informations $\delta$ and $\varphi_{d}$ [19].

$$
\bar{W}_{E}=\mathbf{K}_{E}\left(\vartheta_{e},{ }^{s} \gamma\right) \bar{i}_{\alpha \beta}+\bar{K}_{m}\left(\varphi_{d}\right) \delta
$$

Where $\bar{W}_{E}=\left[\begin{array}{lll}F_{x} & F_{y} & T\end{array}\right]^{T}$ and $\bar{i}_{\alpha \beta}=$ $\left[\begin{array}{llllllll}{ }^{1} i_{\alpha} & { }^{1} i_{\beta} & \ldots & { }^{s} i_{\alpha} & s^{i_{\beta}} & \ldots & { }^{n} i_{\alpha} & n_{s} i_{\beta}\end{array}\right]^{T} \quad$ are the mechanical $x-y$ forces and torque vector and the total vector of the $\alpha-\beta$ axis currents, respectively. $\vartheta_{e}=p \vartheta_{m}$ is the electrical angular position of the rotor and ${ }^{s} \gamma$ is the angular position between the magnetic axis of phase ${ }^{s} u$ and the $x$-axis. Matrix $\mathbf{K}_{E}\left(\vartheta_{e},{ }^{s} \gamma\right) \in \mathbb{R}^{3 \times 2 n_{s}}$ is composed of $n_{s}$ sub-matrices ${ }^{s} \mathbf{K}_{E}\left(\vartheta_{e},{ }^{s} \gamma\right)$ as described in [17].

The reference currents needed to generate the required radial force and torque with the minimum copper losses can be calculated according to

$$
\bar{i}_{\alpha \beta}^{*}=\mathbf{K}_{E}^{+}\left[\bar{W}_{E}^{*}-\bar{K}_{m}\left(\varphi_{d}\right) \delta\right]=\mathbf{K}_{E}^{+}\left[\left(\bar{W}_{E}^{*}-k_{m}\left[\begin{array}{c}
m \\
n \\
0
\end{array}\right]\right]\right.
$$

where $m$ and $n$ are the $x-$ and $y-$ axis displacements respectively, $k_{m}$ is the magnetic radial stiffness and matrix $\mathbf{K}_{E}^{+}$is the pseudo-inverse matrix of $\mathbf{K}_{E}$. Indeed, $\mathbf{K}_{E}$ is a rectangular matrix, hence a proper strategy is needed to compute its inverse. The copper losses minimization was chosen in [17] leading to the calculation of $\mathbf{K}_{E}^{+}$as in (3).

$$
\mathbf{K}_{E}^{+}=\mathbf{K}_{E}^{T}\left(\mathbf{K}_{E} \mathbf{K}_{E}^{T}\right)^{-1}
$$




\section{SPOC fault condition}
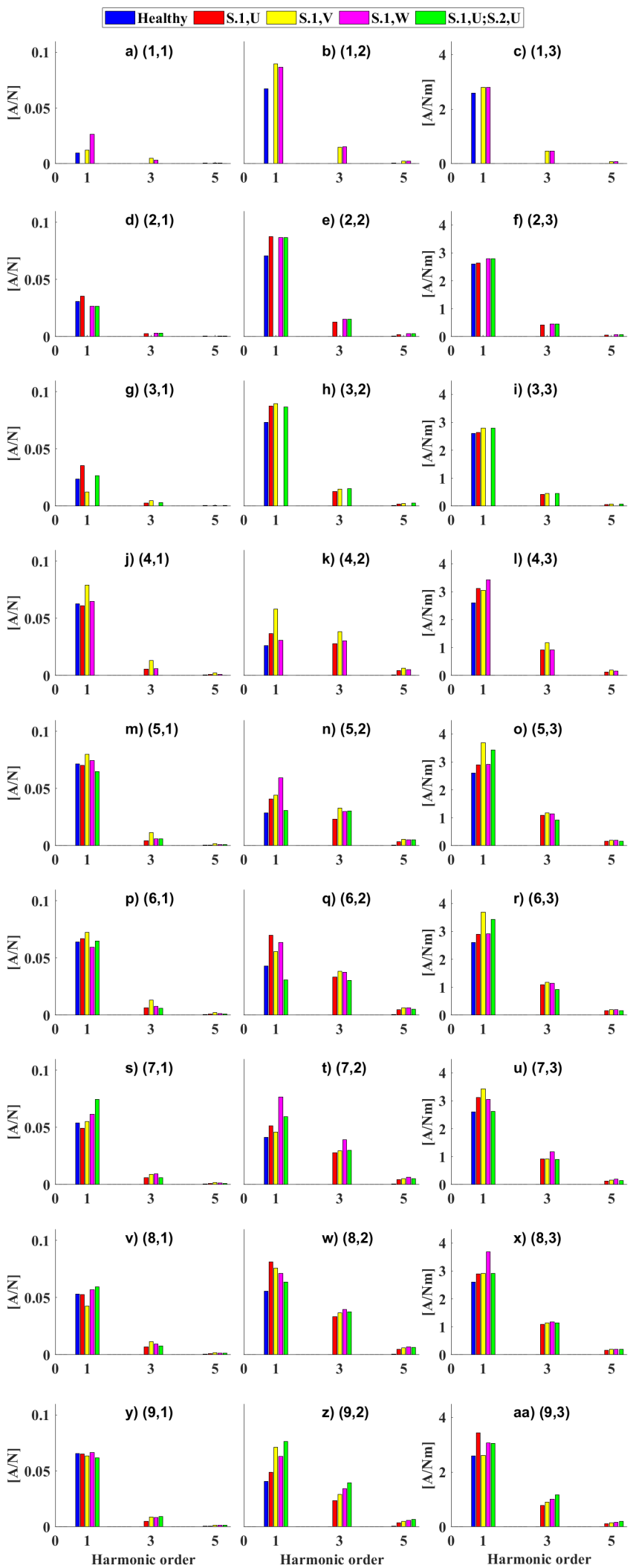

It is convenient to develop the model of the SPOC fault in the phase current domain, therefore the matrix formulation (1) is rewritten in

$$
\bar{W}_{E}=\mathbf{K}_{u v w}\left(\vartheta_{e}{ }^{s} \gamma\right) \bar{i}_{u v w}+\bar{K}_{m}\left(\varphi_{d}\right) \delta
$$

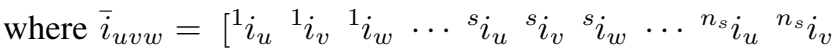
$\left.{ }^{n_{s}} i_{w}\right]^{T}$ and matrix $\mathbf{K}_{u v w}\left(\vartheta_{e},{ }^{s} \gamma\right) \in \mathbb{R}^{3 \times 3 n_{s}}$ can be obtained as follow

$$
\mathbf{K}_{u v w}\left(\vartheta_{e},{ }^{s} \gamma\right)=\mathbf{K}_{E}\left(\vartheta_{e},{ }^{s} \gamma\right){ }^{9} \mathbf{T}_{\mathbf{C}}
$$

where ${ }^{9} \mathbf{T}_{\mathbf{C}}$ is the nine-phase amplitude invariant Clarke transformation and expressed

$$
{ }^{9} \mathbf{T}_{\mathbf{C}}=\left[\begin{array}{ccc}
\mathbf{T}_{\mathbf{C}} & 0 & 0 \\
0 & \mathbf{T}_{\mathbf{C}} & 0 \\
0 & 0 & \mathbf{T}_{\mathbf{C}}
\end{array}\right]
$$

where $\mathbf{T}_{\mathbf{C}}$ is three-phase amplitude invariant Clarke transformation.

When a SPOC fault appears in a sector, the current of the faulty phase goes to zero while the healthy phases will carry currents of same amplitude but opposite phase. Therefore, the SPOC fault in the generic sector $s$ can be modelled introducing the vectors

$$
\begin{aligned}
& \mathbf{F}_{u}=\left[\begin{array}{lll}
0 & 1 & -1
\end{array}\right]^{T} \\
& \mathbf{F}_{v}=\left[\begin{array}{lll}
1 & 0 & -1
\end{array}\right]^{T} \\
& \mathbf{F}_{w}=\left[\begin{array}{lll}
1 & -1 & 0
\end{array}\right]^{T}
\end{aligned}
$$

when the faulty phase is $u, v$ and $w$, respectively. Indeed, the sub-matrix ${ }^{s} \mathbf{K}_{u v w \varkappa}$ of the faulty sector can be written as

$$
{ }^{s} \mathbf{K}_{u v w, \varkappa}\left(\vartheta_{e},{ }^{s} \gamma\right)={ }^{s} \mathbf{K}_{u v w}\left(\vartheta_{e},{ }^{s} \gamma\right) \mathbf{F}_{\varkappa}
$$

where the subscript $\varkappa$ stands for $u, v$ and $w$ depending on the faulty phase. It is now possible to build matrix $\mathbf{K}_{u v w}\left(\vartheta_{e},{ }^{s} \gamma\right)$ considering any open circuited phase. For instance, matrix $\mathbf{K}_{u v w}\left(\vartheta_{e},{ }^{s} \gamma\right)$ for a fault in phase $\varkappa$ of sector $s$ becomes

$$
\begin{aligned}
\mathbf{K}_{u v w, s \varkappa}= & {\left[{ }^{1} \mathbf{K}_{u v w}\left(\vartheta_{e},{ }^{1} \gamma\right) \ldots{ }^{s} \mathbf{K}_{u v w, \varkappa}\left(\vartheta_{e},{ }^{s} \gamma\right)\right.} \\
& \left.\ldots{ }^{n_{s}} \mathbf{K}_{u v w}\left(\vartheta_{e},{ }^{n_{s}} \gamma\right)\right]
\end{aligned}
$$

In a similar manner the SPOC fault in two sectors can also be represented. The machine discussed in this paper is composed of three sectors, hence at least one of them has to be healthy in order to provide a controllable suspension force and motoring torque. Matrix $\mathbf{K}_{u v w, s \varkappa}$ is in general rectangular $\left(\in \mathbb{R}^{3 \times 3 n_{s}-2}\right.$ or $\in \mathbb{R}^{3 \times 3 n_{s}-4}$ for SPOC fault in one or two sectors, respectively), hence its pseudo inverse $\mathbf{K}_{u v w, s \varkappa}^{+}$is computed by means of (3) in order to obtain the reference phase current values.

Figure 2 shows the harmonic spectrum of coefficients in $\mathbf{K}_{u v w, s \varkappa}^{+}$. The $(m, n)$ in the title of every subfigure represents the location of coefficient in the matrix $\mathbf{K}_{u v w, s \varkappa}^{+}$. Blue bars represents the harmonics of coefficients in healthy condition so they can be found in every subfigure. Red,

Fig. 2. Harmonic spectrum of the coefficients in $\mathbf{K}_{u v w, s \varkappa}^{+}$. 
yellow and pink bars are related to SPOC fault in phase $u, v, w$ of sector 1 respectively and they do not appear in the first, second and third row respectively as their value is zero. Finally, green bars are related to SPOC faults in phase $u$ of sector 1 and sector 2 . Therefore, both the first row and the fourth row do not contain green bars. It can be noticed that in healthy condition harmonic orders higher than one are very small, hence can be neglected. Instead, higher order coefficients cannot be neglected in case of SPOC fault in one sector or two sectors. Indeed, Fig. 2 shows that the harmonic amplitudes of the $3^{\text {rd }}$ and $5^{\text {th }}$ orders are remarkable and in some cases comparable with the first harmonic order (see green bars in $(5,2)$ and $(6,2))$.

The coefficients can be represented by sinusoidal functions and implement in the control board. It is straightforward to notice that it is computationally heavier to operate during a fault because of the higher number of harmonics to include in order properly represent the force and torque coefficients.

\section{Finite ElEments Simulation Results}

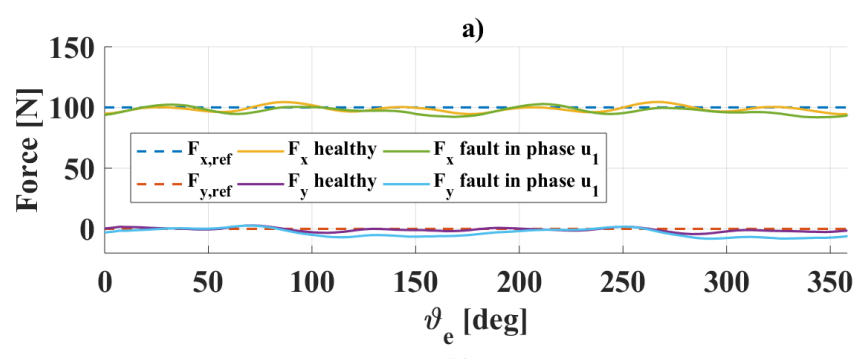

b)

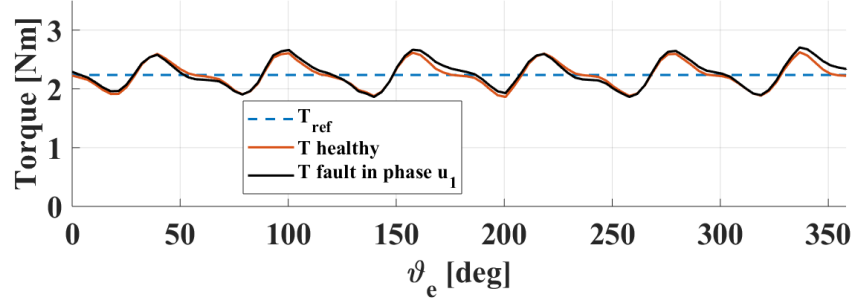

Fig. 3. FE simulation results for the radial force and torque generation in both healthy condition and SPOC fault of phase $u_{1}$ : a) force generation; b) torque generation.

This section shows the FE simulation results obtained to validate the proposed fault tolerant technique. The FE software employed to perform the simulations is MagNet 7.8.3. Three FE multi-static simulations have been performed in order to evaluate the force and torque production in healthy condition, for a SPOC fault in phase $u_{1}$ and for a SPOC fault in phases $u_{1}$ and $v_{2}$. The $x-y$ axis components of the reference force and the reference torque are set equal to $100 \mathrm{~N}, 0 \mathrm{~N}$ and $2 \mathrm{Nm}$, respectively. Figures 3 and 4 a) and b) show the results for the $x-y$ axis force and torque generation, respectively. As it can be qualitatively observed the proposed SPOC fault tolerant technique is capable of producing the required force and

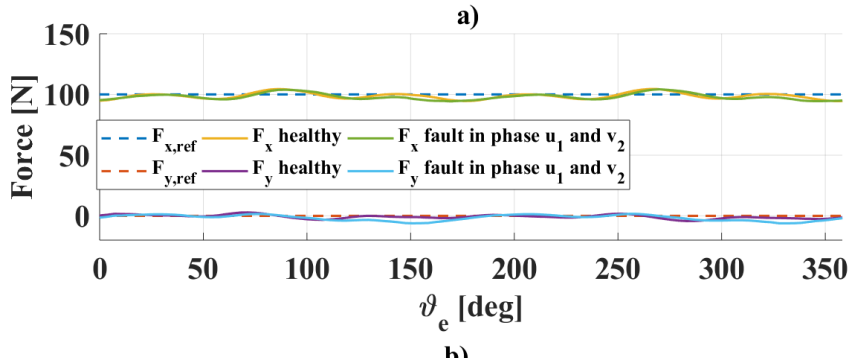

b)

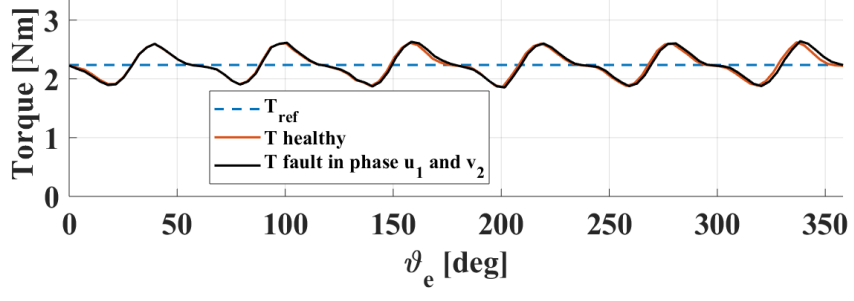

Fig. 4. FE simulation results for the radial force and torque generation in both healthy condition and SPOC fault of phases $u_{1}$ and $v_{2}$ : a) force generation; b) torque generation.

torque without significantly increasing their ripples. This can be quantified in terms of Total Harmonic Distortion (THD). Indeed, the THD of the $x-$ axis force increases from $3.6 \%$ to $4.3 \%$ when a the SPOC fault appears in phase $u_{1}$ while the one of the torque from $13.7 \%$ to $14.5 \%$. Similar THD values are obtained for a SPOC fault in phases $u_{1}$ and $v_{2}$.

\section{Numerical Simulation Results}

The numerical simulation has been run in the MatlabSimulink environment. Figure 5 shows the simulation block of the BM. The current and speed are controlled by means of conventional PI controllers while the radial position loop relies on PID controllers. All controllers are implemented in discrete. The sample time is $50 \mu \mathrm{s}$. The coefficients block and machine block are implemented in healthy and faulty conditions so that models can be set to different states by a Fault signal. The machine block is build up by the mathematical model of multi-sector permanent magnet machines.

Figures 6 a) and b) show the $x-y$ axis position feedback, $x-y$ axis generated force, while Fig. 7 a) and b) show the rotation speed and generated torque. The system is simulated in healthy condition between 0 and $0.1 \mathrm{~s}$. From $0.1 \mathrm{~s}$ to 0.15 $\mathrm{s}$, phase $u_{1}$ is open circuited and from $0.15 \mathrm{~s}$ to $0.2 \mathrm{~s}$ both phases $u_{1}$ and $u_{2}$ are faulty. It can be observed that the rotor suspension is stable during the entire simulation and that the position oscillation slightly increases during faulty operations. In each period a force disturb of $100 \mathrm{~N}$ is applied in the $x$ - axis direction causing a small position oscillation as can be appreciated from the figure. After $0.01 \mathrm{~s}$ a speed reference is applied in the form of a slope leading to an 


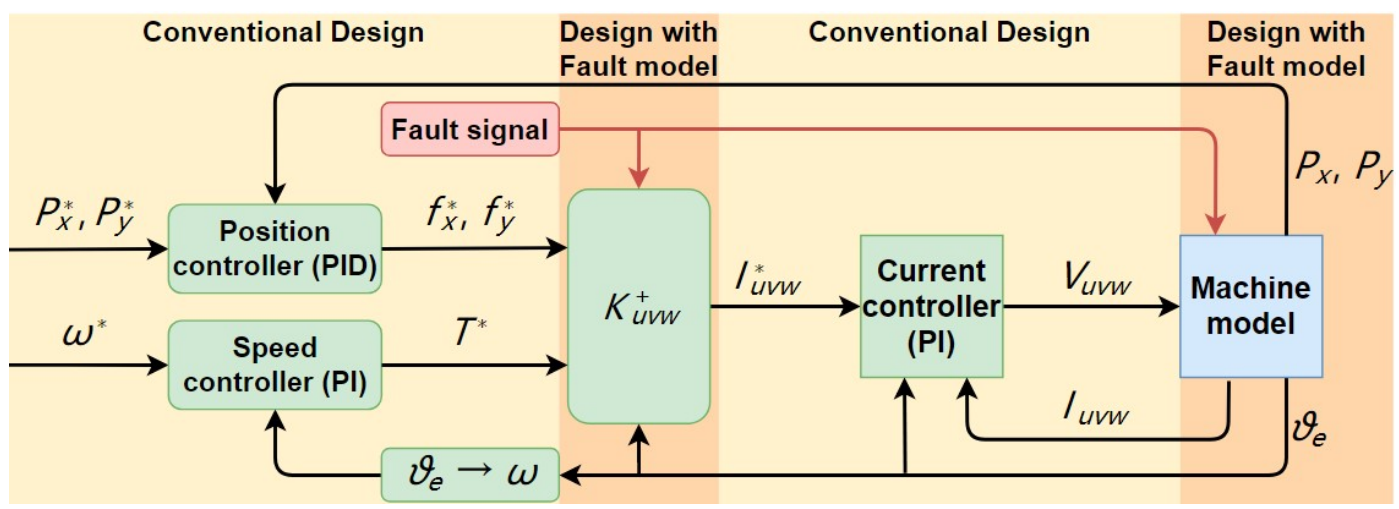

Fig. 5. Simulation diagram of Multi-sector the bearingless machine.

increase of torque production. The speed reached its rated value in $0.07 \mathrm{~s}$. A $1 \mathrm{Nm}$ load is applied to the machine at $0.09 \mathrm{~s}$. It can be noticed that the torque ripple increases during the faulty operations considered. That is caused by the performance degradation of the current PI controllers during the fault. The phase currents that circulate in sectors 1,2 and 3 during the described simulation are displayed in Fig. 8 a), b) and c), respectively.
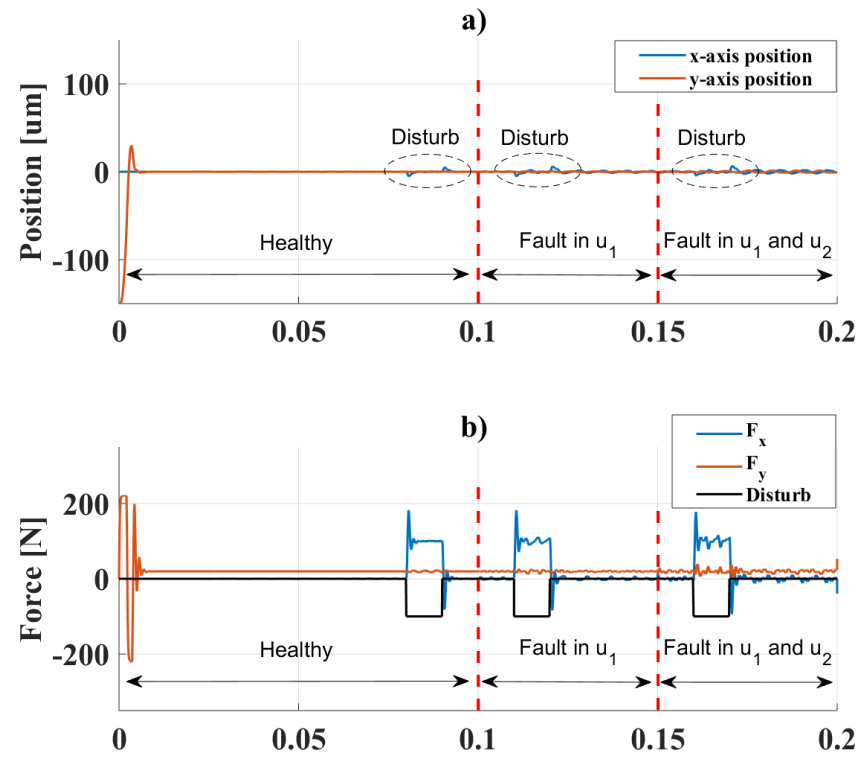

Fig. 6. Numerical simulation results for healthy condition, SPOC fault in sector 1 and SPOC fault in both sector 1 and 2: a) $x-y$ axis position feedback; b) $x-y$ axis force.

\section{CONCLUSION}

The mathematical model of the radial force and electromagnetic torque generation have been presented for both healthy and single-phase open-circuit conditions and the fault tolerant control strategy has been derived. The force and

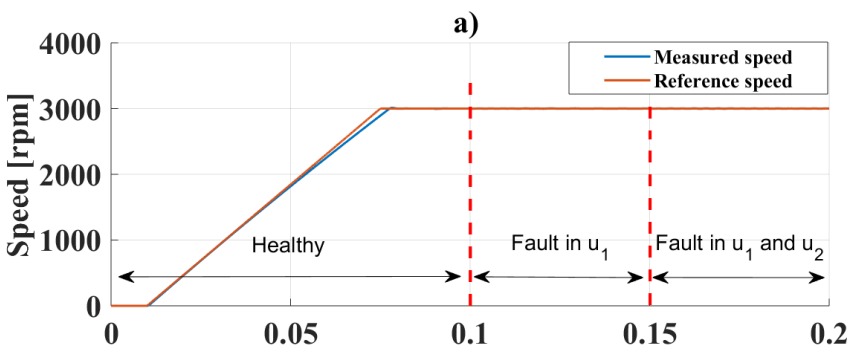

b)

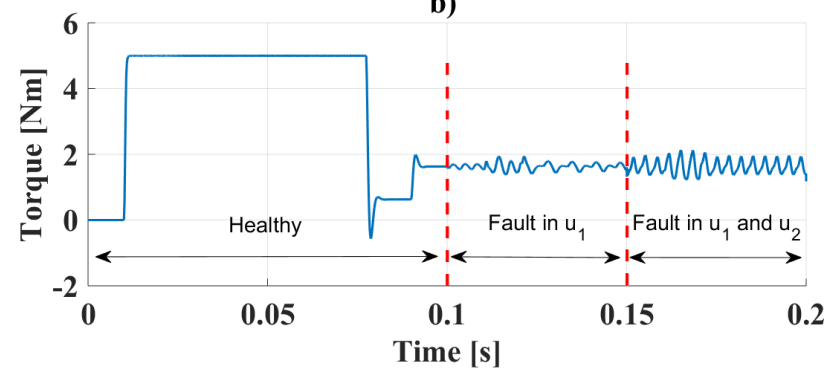

Fig. 7. Numerical simulation results for healthy condition, SPOC fault in sector 1 and SPOC fault in both sector 1 and 2: a) rotation speed; b) torque generation.

torque generation has been validated with FE simulations showing a small increase of the THD during the fault. Finally, the bearingless machine performance was verified in the Matlab-Simulink environment.

\section{REFERENCES}

[1] A. Chiba, T. Fukao, O. Ichikawa, M. Oshima, M. Takemoto, and D. G. Dorrell, Magnetic bearings and bearingless drives. Elsevier, 2005.

[2] A. Chiba, M. A. Rahman, and T. Fukao, "Radial force in a bearingless reluctance motor," IEEE Transactions on Magnetics, vol. 27, no. 2, pp. 786-790, March 1991.

[3] — "Radial force in a bearingless reluctance motor," IEEE Transactions on Magnetics, vol. 27, no. 2, pp. 786-790, March 1991.

[4] A. O. Salazar and R. M. Stephan, "A bearingless method for induction machines," IEEE Transactions on Magnetics, vol. 29, no. 6, pp. 29652967, Nov 1993. 


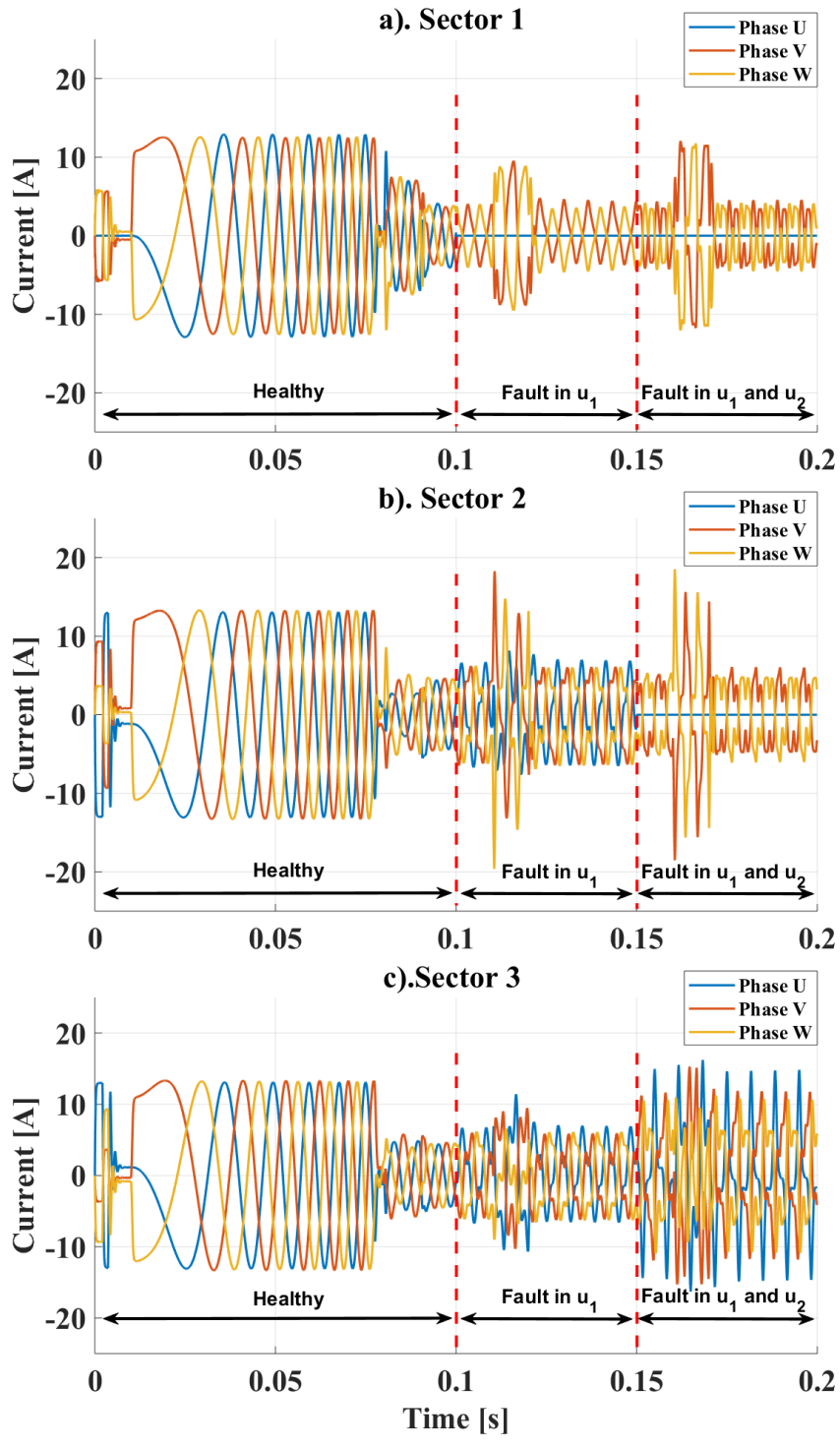

Fig. 8. Three-phase currents in three sectors: a) Sector 1; b) Sector 2; c) Sector 3 .

[5] Y. Okada, N. Yamashiro, K. Ohmori, T. Masuzawa, T. Yamane, Y. Konishi, and S. Ueno, "Mixed flow artificial heart pump with axial self-bearing motor," IEEE/ASME Transactions on Mechatronics, vol. 10, no. 6, pp. 658-665, Dec 2005.

[6] J. Asama, D. Kanehara, T. Oiwa, and A. Chiba, "Development of a compact centrifugal pump with a two-axis actively positioned consequent-pole bearingless motor," IEEE Transactions on Industry Applications, vol. 50, no. 1, pp. 288-295, Jan 2014.

[7] L. Yu, Z. Zhang, Y. Shi, and W. Lu, "Modeling and analysis of suspension force of a new bearingless reluctance machine with independent dc bias winding," IEEE Transactions on Magnetics, vol. 54, no. 11, pp. 1-5, Nov 2018.

[8] H. Jia, J. Wang, M. Cheng, W. Hua, and S. Fei, "Mathematical model of radial suspending force for a new stator-permanent magnet bearingless machine," IEEE Transactions on Magnetics, vol. 51, no. 11, pp. 1-4, Nov 2015.

[9] W. K. S. Khoo, K. Kalita, and S. D. Garvey, "Practical implementation of the bridge configured winding for producing controllable transverse forces in electrical machines," IEEE Transactions on Magnetics, vol. 47, no. 6, pp. 1712-1718, June 2011.
[10] J. Huang, B. Li, H. Jiang, and M. Kang, "Analysis and control of multiphase permanent-magnet bearingless motor with a single set of half-coiled winding," IEEE Transactions on Industrial Electronics, vol. 61, no. 7, pp. 3137-3145, July 2014.

[11] E. Severson, R. Nilssen, T. Undeland, and N. Mohan, "Dual-purpose no-voltage winding design for the bearingless ac homopolar and consequent pole motors,' IEEE Transactions on Industry Applications, vol. 51, no. 4, pp. 2884-2895, July 2015.

[12] A. CHIBA, "Principles and characteristics of a reluctance motor with windings of magnetic bearing," Proc. of Int'l Power Electronics Conf. (IPEC-Tokyo), 1990, 1990. [Online]. Available: https://ci.nii.ac.jp/naid/10016970405/en/

[13] and and and, "Principle and simulation of a 5-phase bearingless permanent magnet-type synchronous motor," in 2008 International Conference on Electrical Machines and Systems, Oct 2008, pp. 11481152.

[14] H. Jiang, J. Huang, and M. Kang, "Principle and realization of a 5phase pm bearingless motor drive," in 2009 IEEE 6th International Power Electronics and Motion Control Conference, May 2009, pp. 1852-1857.

[15] X. L. Wang, Q. C. Zhong, Z. Q. Deng, and S. Z. Yue, "Currentcontrolled multiphase slice permanent magnetic bearingless motors with open-circuited phases: Fault-tolerant controllability and its verification," IEEE Transactions on Industrial Electronics, vol. 59, no. 5, pp. 2059-2072, 2012.

[16] M. Ooshima, A. Kobayashi, and T. Narita, "Stabilized suspension control strategy at failure of a motor section in a d-q axis current control bearingless motor," in 2015 IEEE Industry Applications Society Annual Meeting, Oct 2015, pp. 1-7.

[17] G. Valente, L. Papini, A. Formentini, C. Gerada, and P. Zanchetta, "Radial force control of multi-sector permanent magnet machines for vibration suppression," IEEE Transactions on Industrial Electronics, vol. PP, no. 99, pp. 1-1, 2017.

[18] G. Valente, A. Formentini, L. Papini, C. Gerada, and P. Zanchetta, "Performance improvement of bearingless multisector pmsm with optimal robust position control," IEEE Transactions on Power Electronics, vol. 34, no. 4, pp. 3575-3585, April 2019.

[19] G. Valente, L. Papini, A. Formentini, C. Gerada, and P. Zanchetta, "Open-circuit fault tolerant study of bearingless multi-sector permanent magnet machines," in 2018 International Power Electronics Conference (IPEC-Niigata 2018 -ECCE Asia), May 2018, pp. 40344041. 